\title{
The History and Sociology of Computer Science and Technology. Conclusion. (4/4)
}

\author{
Camille Akmut
}

January 14,2020

Abstract: review of available literature and source materials.

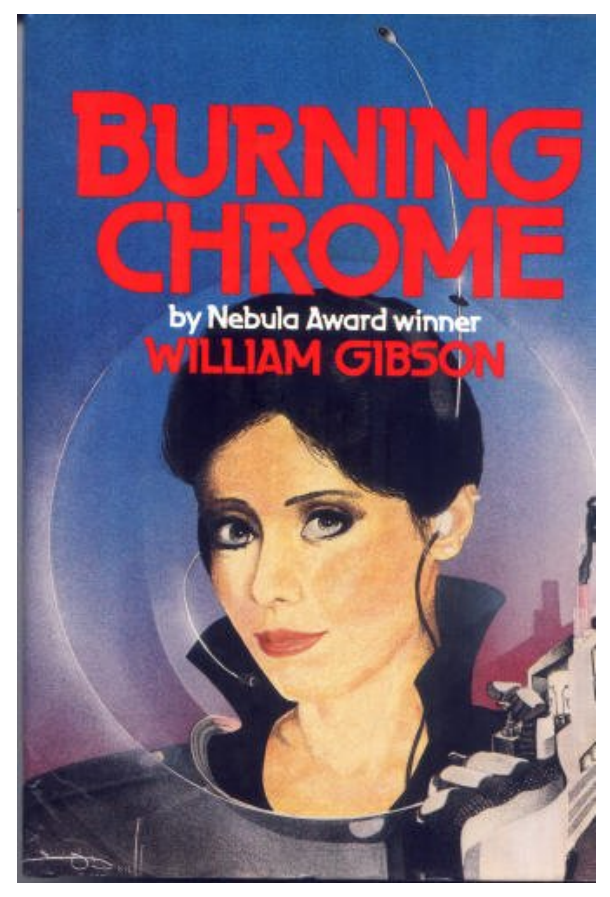

"There are, according to Leibniz, an infinite number of possible worlds" 


\section{WRITINGS}

Primary sources.

- Ellis, Clarence. 2002. "Affective computing. The reverse digital divide." In : Jones. (below)

"This document introduces the kid, Skip Ellis, and his odyssey through computer science. (...) It was obvious to any unbiased observer that the kid born in May, 1943, should be a mathematician within the Academy. [But] the kid was Black, and born in the Chicago ghetto."

\section{— Manning, Chelsea. 2010. "Manning-Lamo Chat Logs".}

"im kind of coming out of a cocoon... its going to take some time, but $i$ hopefully wont be a ghost anymore"

("The first pride was a riot", she wrote 9 years later, to encourage others.)

— Swartz, Aaron. 2004. "Stanford". http://www.aaronsw.com/weblog/001422

Description : A series of posts by 15-year old Aaron recording his first ten days at Stanford. This is the old blog (many entries are gone, but recoverable via archive.org).

"This week we were repeatedly informed about the "unprecedented personal freedom" that we would have at Stanford. Apologies, but I don't see it. (...) The whole thing is a giant privately-owned community, like some sort of Disney World. (...) It's like I've woken up in some sort of libertarian nightmare world, where one company has bought up everything and now tells everyone what to do. Obviously there's no freedom, but the ardent libertarians still say "Look at how free you are! There's no government telling you what to do!" If this is freedom, ... (...) Stanford is comically segregated. (...) segregated by engineering/humanities, why ..."

It is worth noting that already then he was well aware of universities' tracking of networks and students, he wrote: "They register your computer's MAC address so they can track you if you take your laptop anywhere. (...) [the ID card] has a RFID transmitter in it, so they can track us while we walk." This provides further, hitherto not sufficiently explored context for the MIT/JSTOR events.

- Zawinski, Jamie. 2019. [On Uber, Saudi Arabia and Khashoggi]. https://www.jwz.org/blog/2019/11/who-among-us-hasnt-dismemberedsomeone-with-a-bone-saw/

Description : The purported "aesthetic distaste" of hackers for politics... 


\section{ARTICLES}

- Gibson, William. 2011. "The Art of Fiction No. 211" The Paris Review 197.

Description : origins of the word "cyberspace" and other iconoclast information on e.g. his dislike of "cyberpunk" ("That label enabled mainstream science fiction to safely assimilate our dissident influence").

"I ... s[a]t down ... and start[ed] scribbling - infospace, dataspace. ... I got cyberspace on the third try ... I thought it sounded like it meant something while still being essentially hollow."

Perhaps computer scientists and technologists, and the rest, ought to be more careful when readily re-using words such as those. (Let alone the whole BarlowLibertarian spin and baggage added to it since.)

- Gibson, William. 2020. "I was losing a sense of how weird the real world was". The Guardian, 11/01.

Description : another interview with this writer whose influence went far, far beyond literature. Drawing inspiration from programmers; they in turn drew from him.

"I was actually able to write Neuromancer because I didn't know anything about computers. I knew literally nothing. What I did was deconstruct ... the language of people who were already working in the field. I'd stand in the hotel bar at the Seattle science fiction convention listening to these guys who were the first computer programmers I ever saw talk about their work. I had no idea what they were talking about, but that was the first time that I ever heard the word 'interface' used as a verb. And I swooned. Wow, that's a verb. Seriously, poetically that was wonderful."

\section{- Rosenblum, Jonathan. 2019. "Amazon Is on the Attack Against Kshama Sawant". Jacobin, 29/10.}

Description : in public, they insist on distinctions between "technical" matters - their domain, and "political" matters - not theirs. But, meanwhile these companies are some of the most political institutions today. In Seattle, Amazon lobbied to undermine this city councilmember.

'Sawant has pushed a $\$ 15$ minimum wage, landmark renters' rights legislation, free public transit (...) in addition to the record PAC contribution, at least eleven members of Amazon's senior leadership team have donated to pro-corporate city council candidates" 
- Kang, Minsoo. 2017. "The mechanical daughter of Rene Descartes: the origin and history of an intellectual fable" Modern Intellectual History 14(3) : 633-660.

Description : "the idea [that] Descartes [created an] automaton to deal with the loss of his daughter" is re-examined. (They did not miss the reference in Innocence.) Could serve as model for similar studies.

\section{BOOKS}

- Jones, Lee (ed.). 2002. Making It on Broken Promises : African American Male Scholars Confront the Culture of Higher Education. Stylus Publishing.

Description : Includes a testimony by computer scientist Clarence Ellis.

— Ferrieres, Gabrielle. 1950. Jean Cavailles. PUF.

Description : Gabrielle, sister of Jean. With a study of Cavailles by Gaston Bachelard. (Another example of countless texts that haven't been translated yet - at least not to our knowledge.) (Subtitle : combat philosopher.)

- Peterson, T. F.. 2011. Nightwork: A History of Hacks and Pranks at MIT. MIT Press.

Description : pranks, the MIT boys played in the old days ${ }^{1}$ - but, boy have things changed. (Abelson et al. continuously uses the word "neutral(ity)" in their Report, an astonishing 100 times, to describe MIT's position in various matters; but we can also use another : cowardice. Cowardice on a personal level. Cowardice on an institutional one. In him, and a professor of economics, they found gentle, polite, well-behaved servants of centrist sensibilities...)

- Kushner, David. 2003. Masters of Doom: How Two Guys Created an Empire and Transformed Pop Culture. Random House.

Description : John Carmack (code) and John Romero (design), their company id software (ch. 4/5) and emblematic series of video games (ch. 8).

- Ruh, Brian. 2013. Stray dog of anime. The films of Mamoru Oshii. Palgrave Macmillian.

Description : we learn for instance that Oshii's father was a private detective. (The members of Section 9, especially the duo of Batou and Togusa as depicted in Ghost in the Shell 2, remind much more of detectives than regular police.)

\footnotetext{
${ }^{1}$ Putting police cars on one of the domes - that was still pardoned in 1994. But, challenging the interests of corporations, now that was different.
} 
Another monograph is The Cinema of Mamoru Oshii: Fantasy, Technology and Politics by Cavallaro.

\section{TEXTBOOKS}

- Dasgupta, Sanjoy, Papadimitriou, Christos and Vazirani, Umesh. 2008. Algorithms. McGraw-Hill.

Description : These authors achieved the seemingly impossible : writing a modern algorithms book free of any references to corporations (Google, Facebook, Amazon, Microsoft). Their peers - we know - have other plans...

\section{- Hutton, Graham. Programming in Haskell. Cambridge University} Press. (multiple editions)

\section{POPULAR CULTURE}

... depictions of computer scientists and technologists, and their popular culture.

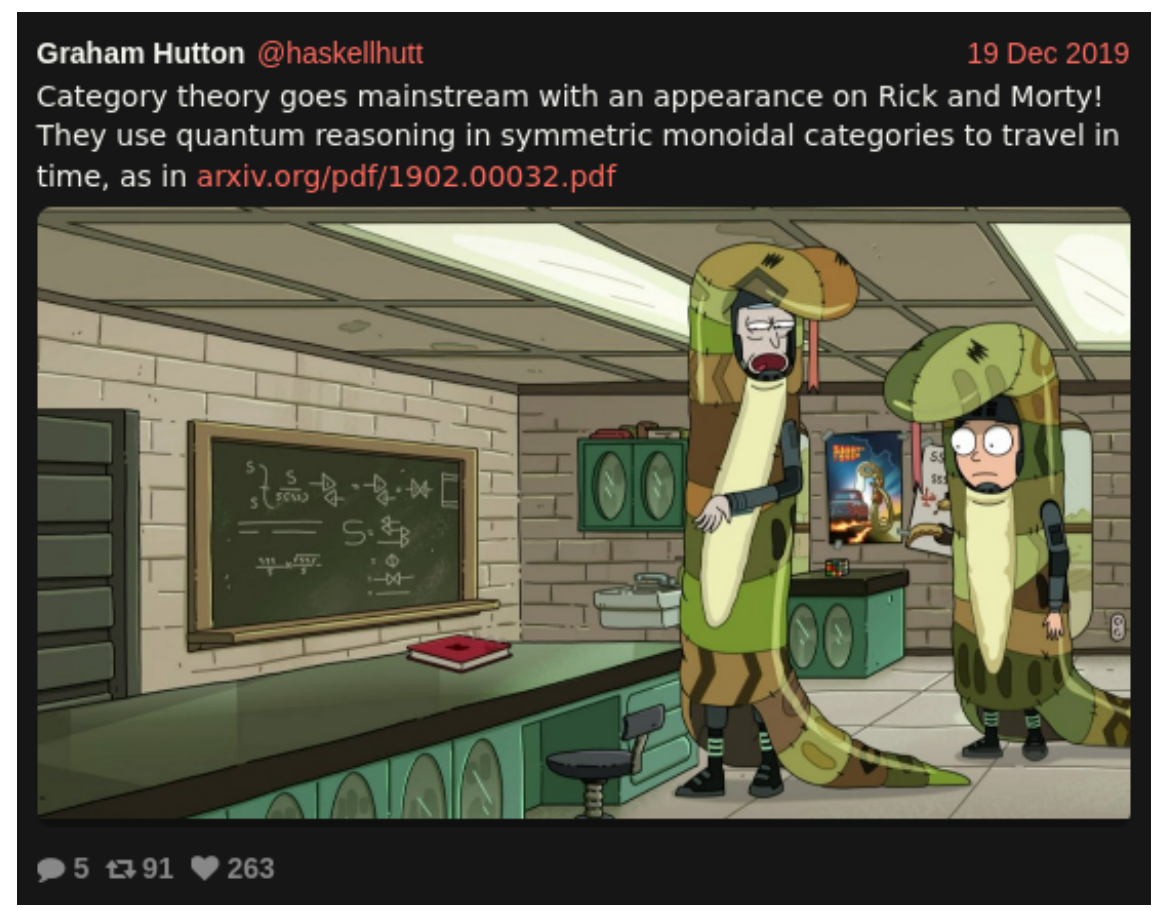

Figure 1: Reflect x2 - Computer scientist comments pop' commentary. 
— Gibson, William. 1986[1970's-1980's]. Burning Chrome.

Description : People often cite Neuromancer, but this is really where it starts. A collection of short stories published before the better-known book : including "Burning Chrome" (first occurrence of the term "cyberspace"), "Johnny Mnemonic", "Fragments of a Hologram Rose"...

“... Ono-Sendai VII. the "Cyberspace Seven" ..."

— The $X$-Files (1993-2002) additions

Description : Gibson wrote the episodes "Kill Switch" and "First Person Shooter", which makes a lot of sense in hindsight (both deal with technology).

— Longo, Robert. 1995. Johnny Mnemonic.

Description : starring Keanu Reeves, four years before The Matrix.

- Crichton, Michael. 1973. Westworld.

— Westworld (2016-...)

Description : the now perhaps better-known series, about androids and their rebellion, at a theme park where the rich can finally live out their (mostly cruel, it turns out) fantasies.

- Cameron, James. Aliens. 1986.

Description : inspiration for Doom.

"Everyone at id was a huge fan of this sci-fi movie. They thought

it would make a great game. (...) a cross between Evil Dead II and Aliens, horror and hell, blood and science." (Kushner 2003)

- Mr. Robot (2015-2019) additions

Description : referenced by Micah Lee (S04E09 discussion in DigitalMunition).

"Nobody in real life uses PGP. Except for The Intercept"

(They did update the keys on their website.)

— Doctor Who, Fourth doctor (1970's-...)

Description : referenced by Conor McBride.

"Oh, come on. Yes, you've failed. But, congratulations! Failure is one of the basic freedoms." 


\section{Bad risk thinking}

\section{What if we live in a simulation?}

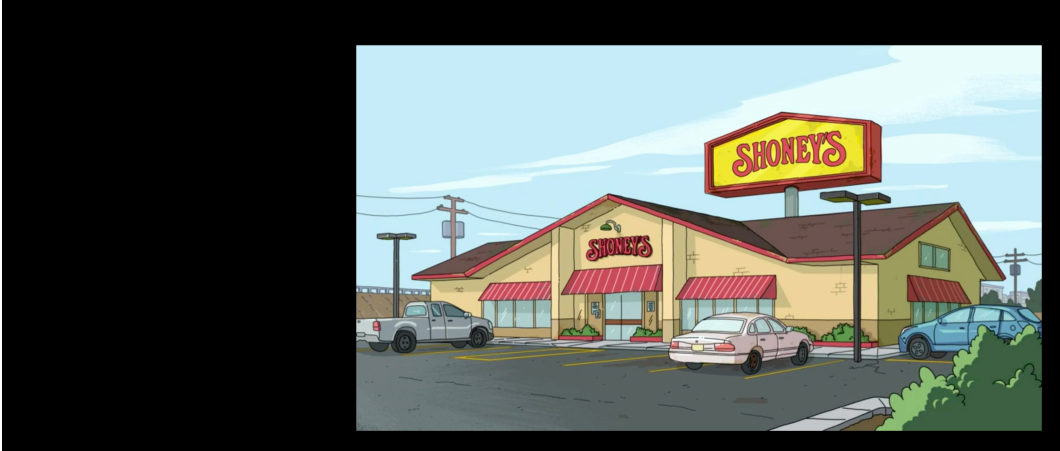

Figure 2: Rick and Morty and cryptography. (J.-P. Aumasson)

\section{Some concluding words}

Scholarly articles, monographs, textbooks, the prose of computer scientists and technologists, computer programs, animation, shares in Big Tech companies, conflict of interest forms, lawsuits, CV's, presentations, the e-mails of bankers. Even cryptographic keys!

With this series of publications, and our work, we hope to have shown that, not only was computer science and technology subjectable to a critical history and sociology, but that it is now one of their prime objects. 


\section{Corrections}

"White Heat" (1949) with James Cagney, not "The Big Heat" (1953) with Glenn Ford was one of the posters in V's room... Though, thematically at least, we'd like to think it would have had a place there too (and perhaps did have one, behind one of the furniture - but, we must use our imagination at this point).

Having mentioned it, I must now also comment on the following : more likely than Alexina is that I saw Daniel Defert at a screening of Pierre Riviere (the other case of an "abnormal" highlighted by Michel Foucault). 


\section{Early history of computing (17th c. onwards)}

"The theme of Leibniz - to free men from slavery by the automation of dull but simple tasks - was next taken up by one of the most unusual figures in modern intellectual history, Charles Babbage (1791-1871)." wrote Goldstine.

To Leibniz he attributed "four great accomplishments to the field of computing": "his initiation of the field of formal logics; his construction of a digital machine; his understanding of the inhuman quality of calculation and the desirability as well as the capability of automating this task; and, lastly, his very pregnant idea that the machine could be used for testing hypotheses." He added (keep in mind the book was released in 1972) : "Even today there are only the beginnings of this type of calculation."

- Goldstine, Herman. 1993. The computer from Pascal to von Neumann. Princeton University Press.

Description : Part 1 covers "up to World War II", starting from 1600.

- Russel, Bertrand. 1992. The philosophy of Leibniz. Routledge.

Description : "Leibniz's philosophy was almost entirely derived from his logic", was the thesis defended by Russel (in his "first strictly philosophical" book per some commentators). His method: "Philosophic truth and falsehood (...) rather than historical fact"...

- Jolley, Nicholas (ed.). 2006. The Cambridge Companion to Leibniz. Cambridge University Press.

"Leibniz had certainly believed that a machine could, in principle, construct demonstrations, make logical inferences. He did not share Descartes's view that "reason" was a kind of supramechanical power of the soul, and he was hopeful about the possibility of actually constructing reasoning machines. But at least at the time of the New Essays, he had seemed inclined, after all, to reserve certain special functions to the soul; he suggests, for example, that it is only the incorporeal "I" which has a true identity and is capable of philosophically confirming it (cf. New Essays II xxvii, A VI.vi; RB 236-37)"

(From Catherine Wilson's contribution on 18th c. reception of Leibniz.) 